\title{
Phaleria macrocarpa Fruits Methanolic Extract Reduces Blood Pressure and Blood Glucose in Spontaneous Hypertensive Rats (SHR)
}

\author{
Dzulsuhaimi Daud ${ }^{1,2,3,}$, Nur 'Amirah Badruzzaman ${ }^{1,3}$, Norrizah Jaafar Sidik ${ }^{3}$, Alene Tawang ${ }^{4}$ \\ ${ }^{1}$ Reproductive Biology \& Toxicology Research Group and ${ }^{2}$ Pharmaceutical \& Life Sciences Community of Research, Universiti Teknologi MARA, 40450 \\ Shah Alam, Selangor, Malaysia. ${ }^{3}$ School of Biology, Faculty of Applied Sciences, Universiti Teknologi MARA, 40450 Shah Alam, Selangor, Malaysia. \\ ${ }^{4}$ Department of Biology, Faculty of Science and Mathematics, Universiti Pendidikan Sultan Idris, 35900 Tanjong Malim, Perak, Malaysia.
}

\author{
ARTICLE INFO \\ Article history: \\ Received on: 12/10/2015 \\ Revised on: 09/11/2015 \\ Accepted on: 04/12/2015 \\ Available online: 26/01/2016 \\ Key words: \\ Phaleria macrocarpa, \\ spontaneous hypertensive \\ rats, blood glucose, blood \\ pressure.
}

\begin{abstract}
Methanolic extract of Phaleria macrocarpa fruits was evaluated for the anti-hypertensive and antihyperglycaemic capacity. For a period of three weeks, 18 male young Spontaneous Hypertensive Rats (SHR) were divided into three experimental groups and received commercial rat pellets as their maintenance diet. At the same duration, SHR in Group 1 received $2 \mathrm{ml} / \mathrm{kg} / \mathrm{day}$ of distilled water and served as a negative control. Meanwhile, SHR in Group 2 and Group 3 received $0.5 \mathrm{mg} / \mathrm{kg} /$ day of Telmisartan (positive control) and 500 $\mathrm{mg} / \mathrm{kg} /$ day P. macrocarpa fruits methanolic extract, respectively. Bodyweight, arterial blood pressure and blood glucose were measured on a weekly basis. All SHR showed significant increased $(p<0.05)$ in their bodyweight but did not differ significantly $(p>0.05)$ between groups. Blood pressure and blood glucose significantly decreased $(\mathrm{p}<0.05)$ in SHR treated with Telmisartan and P. macrocarpa compared to negative control. These results lead us to conclude that $P$. macrocarpa fruits methanolic extract exhibit anti-hypertensive and antihyperglycaemic activities.
\end{abstract}

\section{INTRODUCTION}

Hypertension or high blood pressure is defined in an adult human as a blood pressure greater than or equal to 140 $\mathrm{mmHg}$ of systolic pressure and $90 \mathrm{mmHg}$ of diastolic pressure (Wang et al., 2014). Hypertension is one of the risk factors for cardiovascular diseases, the leading cause of death in developed countries (Susanta-Kumar, 2010; Marya and Bothara, 2013). Hypertension also causes insulin resistance and hyperinsulinemia via increased peripheral vascular resistance and decreased delivery of glucose and insulin to skeletal muscle (Julius et al., 1991). Antihypertensive therapeutic pharmacology includes different type of drugs and grouped into six categories; diuretic, anti-adrenergic, vasodilator, calcium antagonist, angiotensin receptor antagonist and angiotensin converting enzyme (ACE) inhibitor ( $\mathrm{Gu}$ et al., 2012; Jaiprakash et al., 2013). ACE inhibitors are associated with a low rate of adverse side-effects and are the preferred class of anti-hypertensive agents for treating patients with concurrent secondary diseases (Voors et al., 2006; Gu et al., 2012). Other group of drugs, although able to reduce

\footnotetext{
* Corresponding Author

Dzulsuhaimi Daud, School of Biology, Faculty of Applied Sciences, Universiti Teknologi MARA, 40450 Shah Alam, Selangor, Malaysia Email:dzuls990@gmail.com
}

blood pressure, the treatment must be adapted to the particular conditions of each patient (Rivero-Serrano and Tanimoto-Weki, 1999; Shrestha et al., 2012). Despite the fact that there is available a low cost synthetic drugs, local folk also utilised herbs plant for the treatment of hypertensive and other cardiovascular diseases. For example, Mahkota Dewa (Phaleria macrocarpa) is one of the herbs regularly used in traditional remedies among local folks in South East Asia. This plant grows throughout the year in tropical areas, reaching a height of around 1-6 metres (Hendra et al., 2014). $P$. macrocarpa fruit shape is eclipsed, and the colour is green before ripening and red when fully ripped (Backer and Brink, 1965). Large bodies of evidence have accumulated to demonstrate the promising potential of $P$. macrocarpa used in traditional or complementary system to treat human diseases. This plant is traditionally used in South East Asia to treat heart diseases, kidney failure, blood diseases and high blood pressure (Lay et al., 2014). Previous studies reported that, $P$. macrocarpa reduce renal hypertrophy and blood urea nitrogen level in diabetic rats (Triastuti et al., 2009). This plant has been used in many human diseases treatment and prevention owing to its content of useful phytochemicals. Phytochemicals investigation revealed that $P$. macrocarpa is rich in a wide variety of secondary metabolites such as tannins, terpenoids, alkaloids, polyphenols, saponin, flavanoids and steroids (Shodikin, 2010; Hendra et al., 2014). 
The present investigation was conducted to evaluate the potential of $P$. macrocarpa fruits as an anti-hypertensive and antihyperglycaemic agent in spontaneous hypertensive rats (SHR). As far as our literature survey could ascertain, no attempts has been made to investigate the blood pressure and blood glucose reducing effect of $P$. macrocarpa in SHR model. The present study allowed us to investigate the effect of $P$. macrocarpa on both cardiovascular diseases which is hypertension and hyperglycaemic at the same time. This can be achieved due to SHR is well known for their insulin resistance and at the same time also experienced arterial hypertension.

\section{MATERIALS AND METHODS}

\section{Plant materials and preparation of extract}

Fresh fruits of Phaleria macrocarpa were collected from the Faculty of Applied Sciences Botanical Garden of Universiti Teknologi MARA, Shah Alam, Selangor during July-September 2014. The plant was taxonomically identified at the Biology Laboratory, Universiti Teknologi MARA and the voucher specimen was maintained in our research laboratory for the future reference. Plant materials (seedless fruits) were washed, shade dried and pulverized with mechanical grinder to obtain coarse powder. Powdered fruits of P. macrocarpa (200 g) were extracted with 1 litre methanol for three days. The extract was then filtered using a Whatman filter paper to remove the course insoluble particles and evaporated to dryness at $75{ }^{0} \mathrm{C}$ using the rotary evaporator. The dry extract was kept in an airtight container until further use.

\section{Animals and treatments}

The study used young spontaneous hypertensive rats (SHR) bought from Universiti Malaya Animal House. The animals were housed in polyethylene cages (two rats per cage) and maintained with commercial rat pellets and water ad-libitum. The use of animals in this study was monitored by the Research Ethics Committee of the Faculty of Applied Sciences, Universiti Teknologi MARA. Three groups of SHR were used in the three weeks study as follows; Group I as a negative control (SHR treated with $2 \mathrm{ml} / \mathrm{kg}$ bwt of distilled water), Group II as a positive control (SHR orally gavaged with $0.5 \mathrm{mg} / \mathrm{kg}$ b.w.t of Telmisartan) and Group III (SHR orally gavaged with $500 \mathrm{mg} / \mathrm{kg}$ b.w.t of $P$. macrcocarpa fruits methanolic extract). The SHR were given the respective treatment for three weeks. Body weight, blood pressure and blood glucose were recorded on a weekly basis. Body weight was measured with weighing balance, blood pressure was measured using tail-cuff apparatus and blood glucose was estimated with electronic glucometer (Gouveia et al., 2000).

\section{Phytochemicals screening by GC-MS}

Preliminary phytochemicals screening test was conducted to identify the organic constituents in the $P$. macrocarpa fruit according to the qualitative method of Rozianoor et al., (2014). GC-MS analysis was performed using an Agilent-
5973 network system. The chromatographic column used for the analysis was an HP-5 capillary column with a dimension of $30 \mathrm{Mts}$ x $0.32 \mathrm{~mm} \times 0.25 \mu \mathrm{m}$. Helium was used as a carrier gas at a constant flow of $1 \mathrm{ml} / \mathrm{min}$ and an injection volume of $1 \mu \mathrm{L}$. The temperature was increased to $240{ }^{\circ} \mathrm{C}$ at $3{ }^{\circ} \mathrm{C} / \mathrm{min}$. Interpretation on mass spectrum of GS-MS was conducted using the database of the National Institute of Standard and Technology (NIST).

\section{Statistical analysis}

Statistical evaluations were conducted using Statistical Packages for Social Sciences Software (SPSS) version 20 (IBM Inc, Chicago, USA). Results are presented as means \pm SEM. Data being collected at several time intervals were analyzed using repeated measures ANOVA. The difference was assumed to be significant when $\mathrm{p}<0.05$.

\section{RESULTS AND DISCUSSION}

\section{The effect of Phaleria macrocarpa fruits methanolic extract on SHR body weight}

Body weight of spontaneous hypertensive rats (SHR) was significantly $(\mathrm{p}<0.05)$ increased over the duration of experiment in all groups and did not differ significantly $(\mathrm{p}>0.05)$ between groups (Figure 1). Following three weeks of the experiment, the body weight of SHR treated with distilled water (negative control), Telmisartan (positive control) and $P$. macrocarpa methanolic extract increased to $185.34 \pm 2.5$, $189.93 \pm 2.1$ and $183.12 \pm 1.8 \mathrm{~g}$, respectively. Our results are contradictory to the study by Parhizkar and co-workers (2013) who reported that the body weight of rats supplemented with $P$. macrocarpa significantly lower compared to control. Perhaps, this can be explained by the different strain of animal used in both experiments. We utilised spontaneous hypertensive rats (SHR) meanwhile Parhizkar and co-workers (2013) used Sprague Dawley rats. This also may be due to the shorter duration of treatment adopted in this study ( 3 weeks in the current study versus 7 weeks of Parhizkar and co-workers).

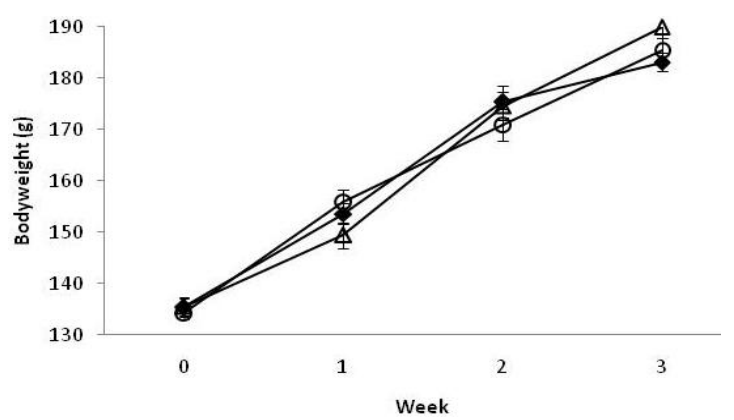

Fig. 1: Body weight of SHR treated with distilled water (o), Telmisartan $(\Delta)$ and $P$. macrocarpa $(\diamond)$. Data are expressed as mean \pm standard error mean $(\mathrm{n}=6)$.

\section{The effect of Phaleria macrocarpa fruits methanolic extract on SHR blood pressure}

Blood pressure was decreased significantly $(\mathrm{p}<0.05)$ in SHR treated with Telmisartan (positive control) and P.macrocarpa 
fruits methanolic extract compared to SHR treated with distilled water (negative control) (Figure 2 and 3). SHR treated with Telmisartan also had lower blood pressure (systolic and diastolic) compared to SHR treated with $P$. macrocarpa. Over three weeks of treatment with distilled water, Telmisartan and P. macrocarpa methanolic extract, SHR systolic blood pressure changed to $175 \pm 3.2,121 \pm 3.5$ and $140 \pm 3.3 \mathrm{mmHg}$, respectively. Meanwhile the diastolic pressure in SHR treated with distilled water, Telmisartan and P. macrocarpa methanolic extract were 132 \pm 3.1 , $78 \pm 4.3$ and $90 \pm 3.1 \mathrm{mmHg}$, respectively.

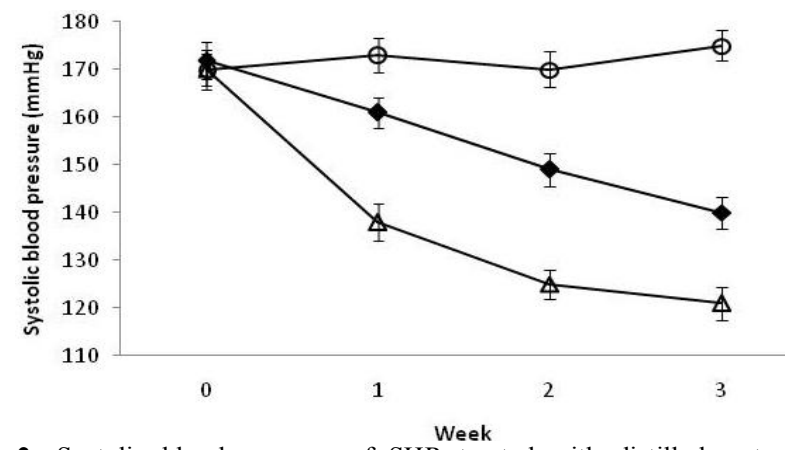

Fig. 2: Systolic blood pressure of SHR treated with distilled water (०), Telmisartan $(\Delta)$ and $P$. macrocarpa $(\downarrow)$. Data are expressed as mean \pm standard error mean $(n=6)$.

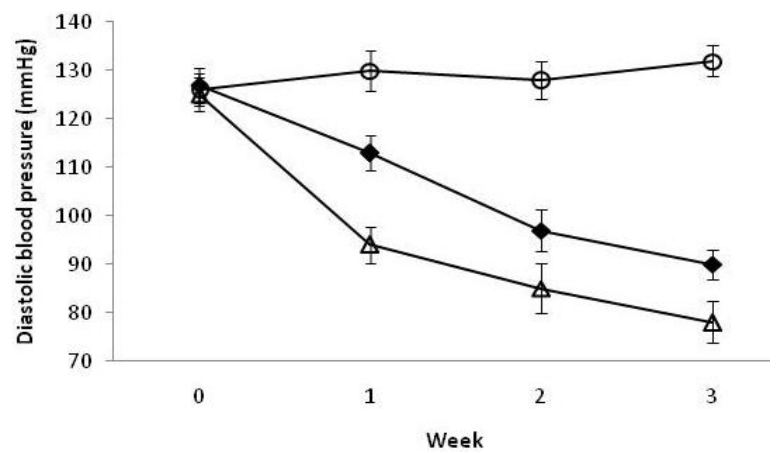

Fig. 3: Diastolic blood pressure of SHR treated with distilled water $(0)$, Telmisartan $(\Delta)$ and $P$. macrocarpa $(\bullet)$. Data are expressed as mean \pm standard error mean $(n=6)$.

The anti-hypertensive activity of $P$. macrocarpa fruits methanolic extract in SHR might be through: inhibition of angiotensin-converting enzymes, acetylcholine-like mechanism, histamine-like mechanism, diuretic action or maybe vasodilation effect. In-vitro investigation showed that, $P$. macrocarpa fruits methanolic extract possesses antihypertensive activity through inhibition of angiotensin-converting enzymes (Yanti et al., 2014). Oshimi and colleague reported that $P$. macrocarpa fruits chloroform extract showed moderate vasodilator activity in Wistar rat aorta (Oshimi et al., 2008). Our data on GC-MS analysis showed that, $P$. macrocarpa fruits methanolic extract contain 2,6,10,14,18,22-Tetracosahexaene (Table 1), a chemical compound with vasodilation effect (Sudha et al., 2013). We postulated that, in SHR, $P$. macrocarpa fruits methanolic extract reduced the blood pressure partly through vasodilation effect. Currently, further investigation is still undergoing in our laboratory to determine the $P$. macrocarpa fruits methanolic extract mode of action in reducing the blood pressure of SHR.

\section{The effect of Phaleria macrocarpa fruits methanolic extract on SHR blood glucose}

Blood glucose were significantly $(\mathrm{p}<0.05)$ reduced in the spontaneous hypertensive rat (SHR) treated with Telmisartan (positive control) and P. macrocarpa compared to SHR treated with distilled water (negative control) (Figure 4). After three weeks of the experiment, the blood glucose of SHR treated with distilled water, Telmisartan and $P$. macrocarpa methanolic extract reduced to $21.9 \pm 1.3,13.7 \pm 1.5$ and $14.3 \pm 1.1 \mathrm{mg} / \mathrm{L}$, respectively. However, blood glucose did not differ significantly $(\mathrm{p}>0.05)$ among SHR treated with Telmisartan and $P$. macrocarpa $(13.7 \pm 1.5 \mathrm{mg} / \mathrm{L}$ vs $14.3 \pm 1.1 \mathrm{mg} / \mathrm{L})$.

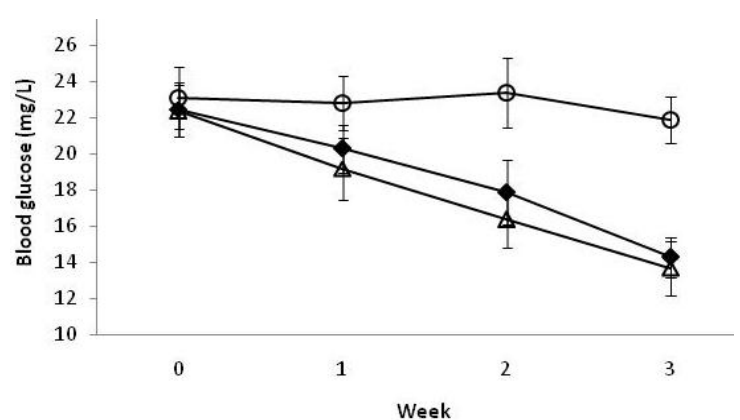

Fig. 4: Blood glucose of SHR treated with distilled water (०), Telmisartan $(\Delta)$ and $P$. macrocarpa $(\diamond)$. Data are expressed as mean \pm standard error mean $(\mathrm{n}=6)$.

Previous author reported that $P$. macrocarpa pericarps show hypoglycaemic activity by inhibiting $\alpha$-glucosidase action (Sugiwati et al., 2006) and stimulates insulin releases through modulation of $\beta$ cell (Abood et al., 2014). However, their data were collected using Sprague Dawley rats. The effect of $P$. macrocarpa on spontaneous hypertensive rats (SHR) blood glucose and the mode of action have never been studied before. In the current study, there is no attempt was made to ascertain the mechanism of the observed hypoglycaemic activity of $P$. macrocarpa fruits methanolic extract in SHR but it can be suggested that it may be acting through either the peripheral or central mechanism. SHR have been used as an experimental model in order to clarify the relationship between insulin resistance and arterial hypertension (Reavan et al., 1989). Mondon and Reavan (1988) observed that, SHR are hyperglycaemic and exhibited insulin resistance. In agreement with Mondon and Reavan (1988), our data showed higher glycaemia values in all animals prior to drugs treatments (Figure 4). It was also documented that muscle glycogen content was lower in SHR both in the fed state and in the fasting state owing to a lower glucose uptake by muscle tissue (Gouveia et al., 2000). We postulated that, in SHR, P. macrocarpa fruits methanolic extract reduced peripheral vascular insulin resistance and increased delivery of glucose and insulin to peripheral tissues, especially skeletal muscle. In addition to, our GC-MS analysis recorded the presence of 2,6,10,14,18,22- 
Tetracosahexaene and 1,2-Benzenedicarboxylic acid, mono (2ethylhexyl) ester in $P$. macrocarpa fruits methanolic extract (Table 1). 2,6,10,14,18,22-Tetracosahexaene and 1,2Benzenedicarboxylic acid is responsible for anti-hyperglycaemic activity in experimental animals as previously reported (Sudha et al., 2013; Akpuaka et al., 2013).

Table 1: Compounds present in P. macrocarpa fruits methanolic extract by GCMS analysis.

\begin{tabular}{lll}
\hline Compounds & RT & Quality \\
\hline 9-Octadecanoic acid(z)-,methyl ester & 23.35 & 99 \\
2,6,10,14,18,22-Tetracosahexaene & 34.86 & 99 \\
1,2-Benzenedicarboxylic acid,mono(2-ethylhexyl) ester & 30.81 & 91 \\
\hline
\end{tabular}

\section{CONCLUSION}

The present findings provided further evidence to the traditional use of the $P$. macrocarpa fruits as an anti-hypertensive and anti-hyperglycaemic agent.

\section{ACKNOWLEDGEMENT}

This work was financially supported by The Faculty of Applied Sciences and Institute of Research Management and Innovation (IRMI), Universiti Teknologi MARA through the Research Intensive Faculty Grant (600-RMI/DANA 5/3/RIF634/2012) and Ministry of Higher Education, Malaysia through the Fundamental Research Grant Scheme (600-RMI/FRGS 5/3 64/2013).

\section{Conflict of Interest and Author's Contribution}

The authors declare that there is no conflict of interests regarding the publication of this paper. All authors were involved in the writing, revision and final approval of the paper.

\section{REFERENCES}

Abood WN, Abdulla MA, Ismail S. Involvement of inflammatory mediators in the gastroprotective action of Phaleria macrocarpa against ethanol-induced gastric ulcer. World Applied Sciences J, 2014;30:344-350.

Akpuaka A, Ekwenchi MM, Dashak DA, Dildar A. Biological activities of characterized isolates of $\mathrm{n}$-hexane extract of Azadirachta indica leaves. New York Sci J, 2013;6:119-124.

Backer C, Brink R. 1965. Flora of Java (Spermatophytes Only), Vol II. Noordhoff, Groningen, Netherlands.

Gouveia LMFB, Kettelhut IC, Foss MC. Abnormalities of glucose metabolism in spontaneously hypertensive rats. Brazillian J Med Bio Res, 2000; 33: 1357-1362.

Gu Q, Burt VL, Dillon CF, Yoon S. Trends in antihypertensive medication use and blood pressure control among United States adults with hypertension. Circulation, 2012; 126: 2105-2114.

Hendra R, Ahmad S, Oskoueian E, Sukari A, Shukor MY. Antioxidant, anti-inflammatory and cytotoxicity of Phaleria macrocarpa (Boerl.) Scheff fruit. BMC Complementary and Alternative Medicine, 2014;11:110-119.

Jaiprakash H, Vinotini K, Min VC. Drug utilization study of antihypertensive drugs in a clinic in Malaysia. Intl J Basic Clin Pharmacol, 2013;2:407-410.

Julius S, Gudbrandsson T, Jamerson K, Shahab ST, Andersson $\mathrm{O}$. The hemodynamic link between insulin resistance and hypertension. $\mathrm{J}$ Hypertension, 1991;9:983-986.
Lay MM, Karsani SA, Banisalam B, Mohajer S, Abd-Malek SN. Antioxidants, phytochemicals and cytotoxicity studies on Phaleria macrocarpa (Scheff.) Boerl seeds. BioMed Research International, 2014; doi.org/10.1155/2014/410184

Marya BH, Bothara SB. 2013. Investigation of antihypertensive activity of leaves of Barleria prionitis in DOCA salt induced hypertensive rats. Intl J Pharm Sci Rev Res, 2013;18:17-19.

Mondon CE, Reaven GM. Evidence of abnormalities of insulin metabolism in rats with spontaneous hypertension. Metabolism, 1988, 37: 303-305.

Oshimi S, Zaima K, Matsuno $\mathrm{Y}$, Hirasawa $\mathrm{Y}$, lizuka $\mathrm{T}$, Studiawan H, Indrayanto G, Zaini NC, Morita H. Studies on the constituents from the fruits of Phaleria macrocarpa. J Nat Med, 2008; 62: 207-210.

Parhizkar S, Che-Zainudin CZB, Dollah MA. Effect of Phaleria macrocarpa on sexual function of rats. Avicenna J Phytomedicine, 2013;3:371-377.

Reavan GM, Chang H, Hoffman BB, Azhar S. Resistance to insulin-stimulated glucose uptake in adipocytes from spontaneously hypertensive rat. Diabetes, 1989;38:1155-1160.

Rivero-Serrano O, Tanimoto-Weki M. 1999. Uso de los medicamentos en la clinica. Mexico: McGraw-Hill Interamericana.

Rozianoor MHW, Nadia MF, Dzulsuhaimi D. In vivo evaluation of hair growth potential of Stachytarpheta jamaicensis ethanolic leaves extract on Sprague Dawley rats. Natural Products An Indian J, 2014;10:17-21.

Shodikin MA. Antimicrobial activity of Mahkota Dewa [Phaleria macrocarpa (Scheff.) Boerl.] leaf extract against Pseudomonas aeruginosa by agar dilution and scanning electron microscopy. Folia Medica Indonesiana, 2010;46:172-178.

Shrestha RK, Khan GM, Thapa P, Koju R. Study of the side effects profile of different antihypertensive drugs among the hypertensive patient. Nepalese Heart J, 2012;9:25-29.

Sudha T, Chidambaram PS, Mohan VR. GC-MS analysis of bioactive components of leaf and stem bark of Kirganelia reticulata Poir (Euphorbiaceae). J Cur Chem Pharm Sci, 2013;3:113-122.

Sugiwati S, Siswati S, Efy A. Antihyperglycemic activity of the Mahkota Dewa [Phaleria macrocarpa (Scheff.) Boerl.] leafs extract as an alpha glucosidase inhibitor. Makara Kesehatan, 2006;13:7478.

Susanta-Kumar R. Antihypertensive therapy: The concepts of management with herbal and synthetic agents for pulmonary hypertension. Intl J Pharm Sci Rev Res, 2010;3:13

Triastuti A, Park HJ, Choi JW. Phaleria macrocarpa suppress nephropathy by increasing renal antioxidant enzyme activity in alloxan induced diabetes rats. Nat Prod Sci, 2009;15:167-172.

Voors AA, van Veldhuisen DJ, van Gilst WH. The current role of ACE inhibitors for secondary prevention in cardiovascular disease; from pathogenesis to clinical practice. Cardiovascular Drugs Therapy, 2006; 20: 69-73

Wang JG, Yan P, Jeffers BW. Effects of amlodipine and other classes of antihypertensive drugs on long-term blood pressure variability: Evidence from randomized controlled trials. J American Soc Hypertension, 2014; 8:340-349.

Yanti AR, Radji M, Mun'im A, Suyatna FD. Effects of the methanol extracts Phaleria macrocarpa (Scheff) Boerl fruits on Angiotensin Converting Enzymes (ACE) activity. Intl J Adv Pharm Bio Chem, 2014; 3: 912-918.

How to cite this article:

Daud D, Badruzzaman N, Sidik NJ, Tawang A. Phaleria macrocarpa Fruits Methanolic Extract Reduces Blood Pressure and Blood Glucose in Spontaneous Hypertensive Rats (SHR). J App Pharm Sci, 2016; 6 (01): 158-161. 